\title{
Paste backfill thermal contraction: Red Lake operations case study
}

\author{
J Oke RockEng Inc., Canada \\ K Hawley Evolution Mining, Canada \\ T Belem Université du Québec en Abitibi-Témiscamingue, Canada
}

A Hashemi RockEng Inc., Canada

\begin{abstract}
One of the earliest attempts at field measurement within hydraulically placed cemented backfill occurred over 20 years ago. Recently, Thompson et al. (2014a) published their findings on capturing thermal expansion within cemented paste backfill (CPB) and cemented hydraulic backfill (CHB). They discovered that the total earth pressure within the $C P B$ following placement is likely to increase at a rate of $30 \mathrm{kPa} /{ }^{\circ} \mathrm{C}$ (i.e. for an $11^{\circ} \mathrm{C}$ temperature increase). However, Thompson and his co-authors' research did not elaborate on the subsequent effects of thermal dissipation (or thermal contraction) in backfill. A comprehensive literature study concluded with no clear evidence of thermal dissipation phenomenon and its effects in backfill. It is hypothesised by the authors that if thermal expansion can occur, then thermal dissipation or contraction is also likely to occur.

Red Lake operation (RLO) of Evolution Mining conducted a field program to capture the characteristics of the $C P B$ during a transition from a plug-cure-main pour strategy to a more aggressive pour strategy (i.e. continuous pour operation). During this investigation, strong evidence of thermal contraction was observed in three of the four instrumented stopes. This paper presents detailed findings of two of the instrumented stopes.
\end{abstract}

Keywords: paste, backfill, instrumentation, thermal contraction, thermal dissipation

\section{Introduction}

Backfilling is a critical component of the mining cycle for many underground mines as it provides ground support to maintain stability in active mining areas and maximises ore recovery through reduced requirements for pillars between stopes. Cemented paste backfill (CPB) is a widely used backfilling material providing efficient and rapid backfilling, engineered strength properties, homogenous material properties, and environmental benefits in enabling the diversion of tailings from surface storage. It is common practice to make the conservative assumption that there is no confining stress acting on the backfill; however, there will be stresses caused by the placement of the backfill, as well as mining-induced stresses. A detailed stability design of the CPB is required to consider confining stress of the backfill. The focus of this paper is to illustrate the behaviour of the CPB during curing and how thermal effects can affect the confining stress condition of the backfill.

Red Lake operation (RLO) of Evolution Mining conducted an instrumentation program to optimise their pour regime. To achieve this goal, the behaviour of the backfill within the stope needed to be captured. For this purpose, instrumentation comprised of total earth pressure cells (TEPCs, to measure total pressure, $\sigma$ ) and piezometers (to measure porewater pressure, $u$ ) were installed together as a cluster so that effective stresses, $\sigma^{\prime}$, could be determined $\left(\sigma^{\prime}=\sigma-u\right)$. Each instrument cluster consisted of one piezometer and at least one TEPC. When possible, three TEPCs were installed, and oriented in three mutually orthogonal axes and secured to a rigid structure (cage) as shown in Figure 1. Capturing orthogonal pressure data enables a more thorough and robust interpretation of data when CPB transitions from a fluid state to a more soil-like 
material. Identification of this transition is extremely useful in predicting whether a specific CPB recipe and pour regime will result in relatively high or low fill fence ${ }^{1}$ pressure conditions.

For this study, the TEPCs have been abbreviated to include the orientation and position of the instruments. $\mathrm{H} 1$ indicates the horizontal TEPC oriented parallel to the fence, reading pressures perpendicular to the fence (stope strike). H2 indicates the horizontal TEPC oriented perpendicular to the fence, reading pressures parallel to the fence (stope width). V1 indicates the vertical pressure reading.
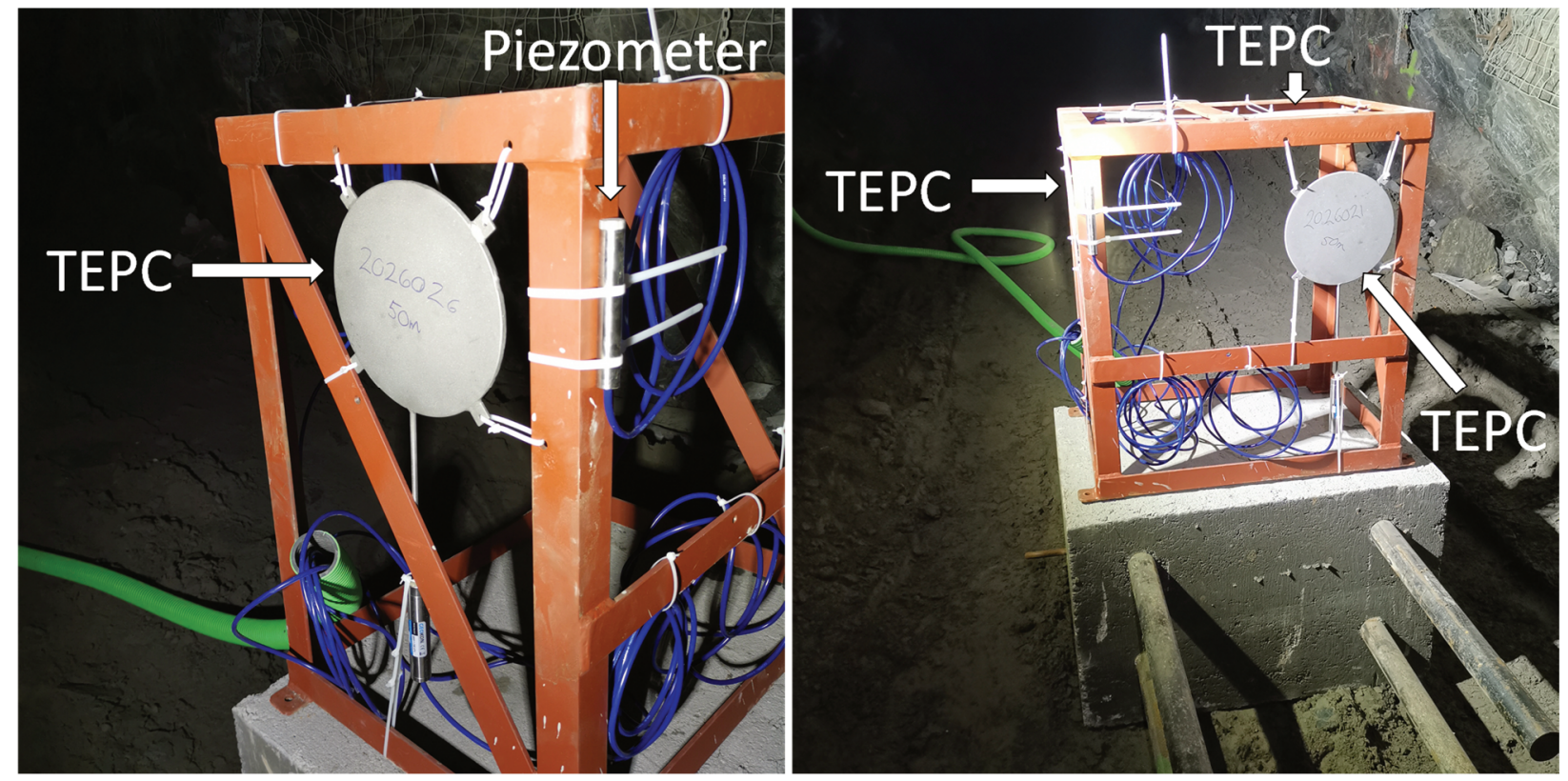

Figure 1 Instrumentation setup for the in-stope instrumentation cluster for stope 321-865-1W Blk 3

\section{Background}

\subsection{Red Lake operations}

RLO has been using CPB since the late 1990s. The site currently has two CPB plants: The Red Lake paste plant, that operates as a batch mixing process, and the Campbell paste plant, that is a continuous pouring system. Both plants feed various areas of the mine through an extensive underground distribution system. Prior to this study, a plug-cure-main pouring strategy was implemented on all longhole stopes. The cure time was based on a target unconfined compressive strength (UCS) of $100 \mathrm{kPa}$ used to prevent liquefaction. Based on UCS determination, conservative cure times of 36 and 72 hours for 9 and $5 \%$ binder, respectively, were set. Due to stope sequencing, these cure times resulted in the need to transfer back and forth between two stopes to ensure constant placement of paste backfill. Improving these operational delays and inefficiencies are ultimately what led to the implementation of this test program.

\section{Thermal expansion}

Constrained thermal expansion is a phenomenon caused by thermal expansion of backfill material within the confined stope volume with rigid sidewalls (either rock or cured backfill), which was first identified within backfill by Thompson et al. (2014a). This was revealed in their study, when in situ measurement results captured a significant increase in pressure between backfilling pours (i.e. nothing was added to the system).

\footnotetext{
${ }^{1}$ The terminology 'barricade', 'fill fence' and 'bulkhead' are all used within the industry to mean impermeable (generally shotcreted) backfill containment structures. However, at RLO, 'barricade' terminology is used to describe other types of barriers, so 'fill fence' will only be used within this publication.
} 
The increase of pressure on the instruments caused by thermal expansion is contributed by the following factors:

- Instrument design.

- Binder type.

- Binder content.

- Water content.

- Air content.

- Geometry of the stope.

- Elastic modulus of the rock mass (i.e. stiffness of boundary condition).

At this point in time, there is no possible way to predict the extent to which the in situ backfill will undergo thermal expansion resulting in increased pressure readings. Thompson et al. (2014a) captured the constrained thermal expansion effect at Kidd and Williams mine. Thompson et al. (2014b) captured the same at Garson Ramp mine. The constrained thermal expansion effect was also captured at Coleman mine (Oke \& Hashemi 2021).

\subsection{Garson Ramp mine}

Thompson et al. (2014b) captured the constrained thermal expansion phenomenon within hydraulic fill. This phenomenon was recorded using instrumentation on the fill fence at Garson Ramp mine. The instruments read an increase of $40 \mathrm{kPa}$ of pressure (additional) in stope $880-6515$, assumed to be caused by constrained thermal expansion, between the end of the plug pour (pour \#5) and the start of the main pour (pour \#6), with less than a $1^{\circ} \mathrm{C}$ temperature change. Measurements within the brow of this stope and in an additional stope (880-6514) at Garson Ramp, found that there was a thermal expansion pressure of 100-125 kPa between the end of the plug pour and the start of the main pour, with less than a $2^{\circ} \mathrm{C}$ temperature change. Thermal expansion was also identified in the instrumentation following three main pours of stope 880-6514. The final three pours (for a total of six) either saw the pressure being stabilised or decreasing (potential thermal contraction).

\subsection{Coleman mine}

A study at Coleman mine (Oke \& Hashemi 2021) found that an instrument was constrained by the backfill that resulted in thermal expansion effects which saw an increase in pressure readings. At the end of the plug pour, the horizontal pressure measurement read $225 \mathrm{kPa}$. There was a three-day cure period, which registered an increase in temperature of $1-2^{\circ} \mathrm{C}$. This increase in temperature resulted in a pressure increase of $50 \mathrm{kPa}$ acting on the fill fence for a total of $275 \mathrm{kPa}$ by the end of the cure period of the plug pour. It is important to note that the horizontal pressure instruments installed lower on the fill fence only saw a $10 \mathrm{kPa}$ increase for a total pressure reading of $85 \mathrm{kPa}$. For more information on Coleman mine results refer to Oke \& Hashemi (2021).

\subsection{Kidd and Williams mine}

Thompson et al. (2014a) looked into the phenomenon of constrained thermal expansion on pressure cells at Kidd mine and Williams mine. Thermal expansion was observed in moderate binder contents ( $>4 \%$ binder) within CPB. However, when binder was reduced to $2.25 \%$, the phenomenon was not registered by instrumentation. Similarly, at Williams mine, a 3\% binder content did not register the phenomenon, even when there was a temperature change of $6^{\circ} \mathrm{C}$. These results indicate that the thermally correlated pressure increase is highly dependent on the properties of the backfill materials (i.e. tailings, binder quantity, binder type, solid content). 
Thompson et al. (2014a) showed that the highest thermal expansion effect recorded using pressure cells at Kidd mine saw an increased pressure rate of $20-30 \mathrm{kPa} /{ }^{\circ} \mathrm{C}$. The influence of geometry, material properties of the pressure cells, and elastic modulus of the surrounding medium was theoretically accounting for 0.9-1.4 kPa/ $/{ }^{\circ}$ C. Simple lab tests (i.e. instruments placed into a container of water) indicated that instrumentation could account for $0.4-0.5 \mathrm{kPa} /{ }^{\circ} \mathrm{C}$. Laboratory tests conducted on the CPB to study the effects of thermal expansion on the water, air, and other materials within the sample saw $4-10 \mathrm{kPa} /{ }^{\circ} \mathrm{C}$. The difference between field and laboratory values could be due to numerous variables. The most significant may be the difference in stiffness of CPB during testing. Lab testing samples are heated externally (i.e. ovens) immediately after preparation, whereas samples in the field had a temperature increase due to cement hydration as well as through frictional shear during underground transportation through pipeline distribution systems.

\section{$4 \quad$ Paste strength}

At RLO, the plug was either made of $5 \%$ binder or $9 \%$ binder (30-40\% class C fly ash, $60-70 \%$ general use Portland cement). At the site, $9 \%$ binder is primarily used if there are planned inverse stopes underneath the plug or if stope sequencing needs to be sped up. This high binder content is used to limit potential CPB dilution, for both the endwall or if overbreak occurs when mining the stope below. The $5 \%$ binder for the plug is used for the remainder of the stopes. For the main pour (remainder of the stope void), 3 or $5 \%$ binder is used depending on endwall strength requirements and sequencing. However, only $3 \%$ binder (main pour) was used in this study to represent a worst-case scenario pouring regime. Early-age strength testing was conducted on the plug CPB mixtures. An example of the early-age strength samples is shown in Figure 2. At two hours of cure time, the samples are no longer in a liquid state but were very soft, and not selfsupporting enough to undergo a compression test. This is an indication that at two hours, shear strength has started to develop. At six hours, the shape of the casting cylinder was maintained (i.e. self-supporting), but the samples are still too soft to undergo a compression test.
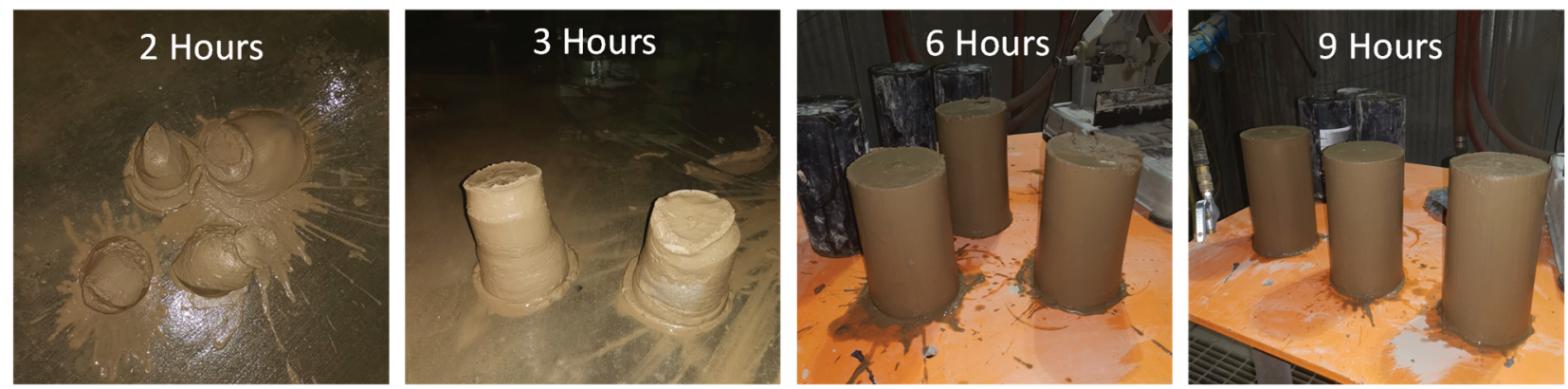

Figure 2 Early-age strength 9\% binder samples from stope 512-595-1E Blk 3. Samples $\leq 6$ hours were not tested

These tests were conducted to capture the strength-time curves for the CPB, as shown in Figure 3. The typical strength-time curves for the 9 and $5 \%$ binder are shown based on historical quality assurance/quality control testing, and the early-age strength testing results are presented. The lower bound strength curve of stope 321-865-1W BLK3 is also presented to illustrate the potential variability of an individual mixture of CPB. The strength curves are important to capture as they provide insight into the elastic modulus of the CPB, which illustrates the potential for how much stress can be transferred into the backfill material.

It is important to note that typical CPB has a solid content (by weight) in the range $70-85 \%$, depending on the tailing's specific gravity (in the range 2.65-4.5 for hard rock mines). The cement hydration process induces a net reduction in volume, similar to that of 'self-desiccation' in concrete. The 'self-desiccation mechanism' results from the fact that the volume of the hydrated cement is less than the sum of the volumes of the non-hydrated cement and the water used in the hydration process. Thus, the hydration process acts like an internal 'sink' for water (Helinski et al. 2007). This results in a lower volume of CPB, which will be a contributing factor to the contraction of the backfill. This phenomenon involves chemical shrinkage that 
results in porewater pressure reduction/dissipation. This phenomenon is not related to thermal change as stated in Belem et al. (2010).

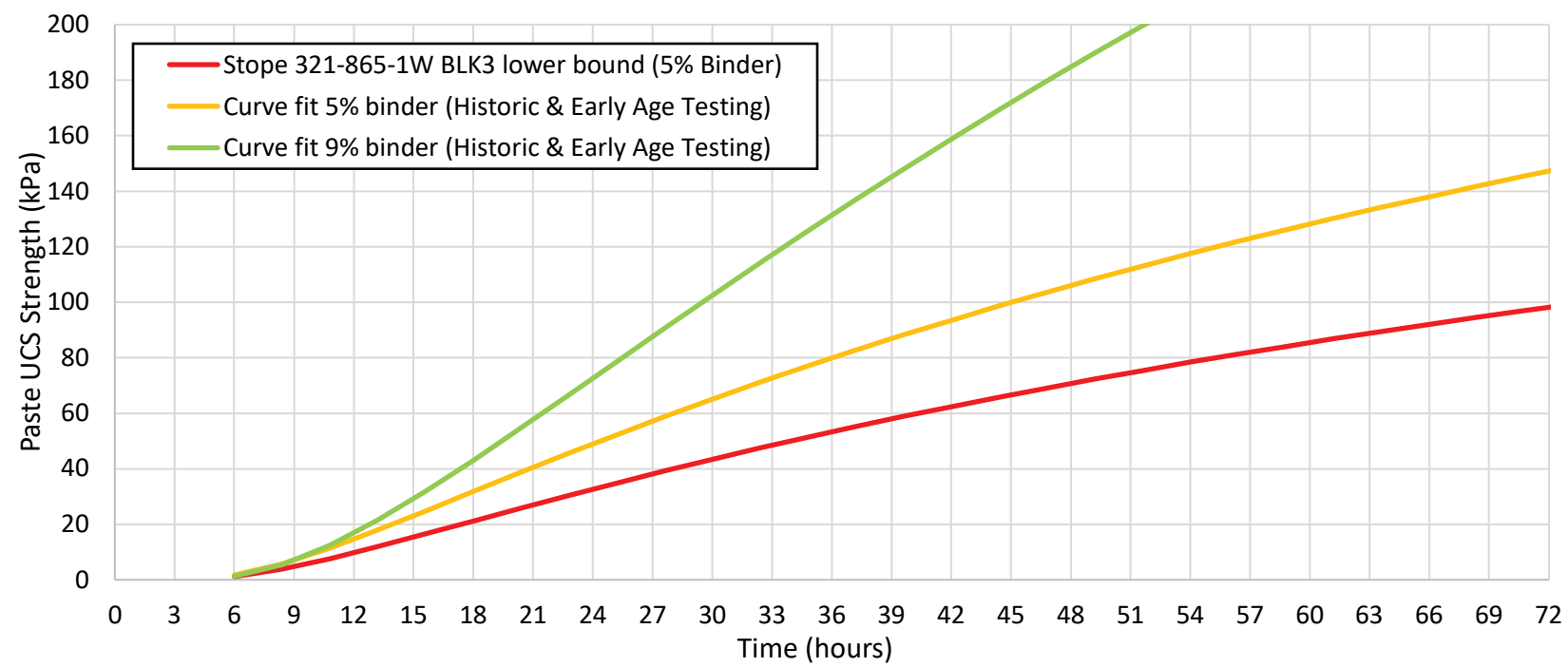

Figure 3 Typical strength-time curves for the 9 and $5 \%$ binder, based on historical quality assurance/quality control testing, and the early-age strength testing results. The lower bound strength curve of stope 321-865-1W BLK3 is also presented

\section{$5 \quad$ Instrumented stopes}

For this study, four different stopes were instrumented for testing: two with $5 \%$ binder and two with $9 \%$ binder. Unfortunately, it was not possible to determine (i.e. directly measure) the fill heights within the stope during the pours. Therefore, all fill heights were required to be inferred.

\subsection{Stope 321-865-1W BLK 3}

Stope 321-865-1W BLK3 was the first stope monitored at RLO. The stope is $16.4 \mathrm{~m}$ high, $23.5 \mathrm{~m}$ long, and $3 \mathrm{~m}$ wide from hanging wall (HW) to footwall (FW) with a dip of $\sim 65^{\circ}$. The shotcrete muck fence was constructed in a drift that was $3 \mathrm{~m}$ wide and $3.4 \mathrm{~m}$ high. Instruments on the muck fence were positioned approximately $3 \mathrm{~m}$ away from the brow and the in-stope instrument cluster was positioned $6.4 \mathrm{~m}$ away. The binder content for the plug was $5 \%$. The total time and pour time required for the stope were 53 and 35 hours, respectively. The instrumentation data was collected for an additional 28 days after the last pour. During this time, the instruments showed generally stabilised pressures with the exceptions of spikes of pressure caused by seismic events from the region. For more information on the stope 321-865-1W BLK3, refer to Oke et al. (2021).

\subsection{Stope 260-876-1 BLK 1}

Stope 260-876-1 BLK1 was the second stope monitored during the program at RLO. The stope is $20.6 \mathrm{~m}$ high, 22.7-26.5 m long, and 2.4-3.4 $\mathrm{m}$ wide from HW to FW with a dip of $\sim 75^{\circ}$. The rebar-reinforced shotcrete fill fence is constructed in a drift that is approximately $4.2 \mathrm{~m}$ wide and $3.4 \mathrm{~m}$ high. The fill fence is positioned $2.1 \mathrm{~m}$ from the brow, as shown in Figure 4. It took only four pours to fill the stope as shown in Table 1. The total time and pour time required for the stope were 51 and 41 hours, respectively.

Data were collected for 31 days after the stope was completely filled with CPB. Figure 5 shows the results from the in-stope instrumentation cluster that was placed $7.6 \mathrm{~m}$ from the brow. Five hours after the main pour was completed, there was a $15 \mathrm{kPa}$ increase in pressure over eight hours (possible thermal expansion) followed by a $10 \mathrm{kPa}$ decrease over five hours (possible chemical shrinkage or thermal contraction). This fluctuation in pressure is not as evident in the fill fence instrument clusters (Figures 6 and 7). The cause of this initial fluctuation is unknown, as no seismic data was captured during the initial spike of pressure. 


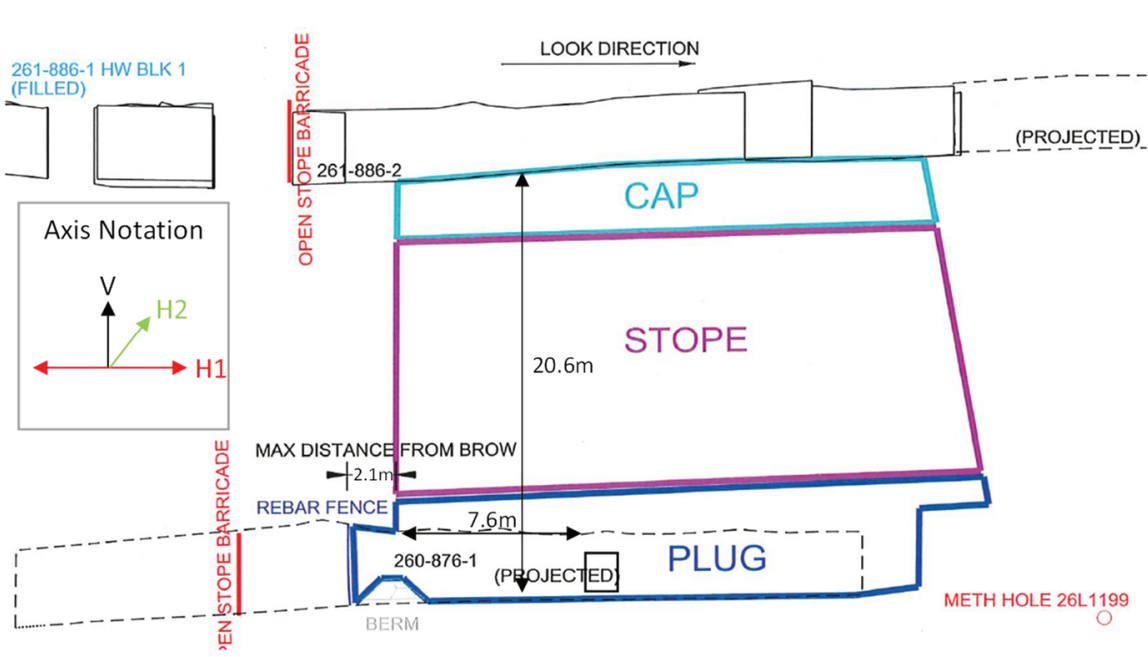

(a)

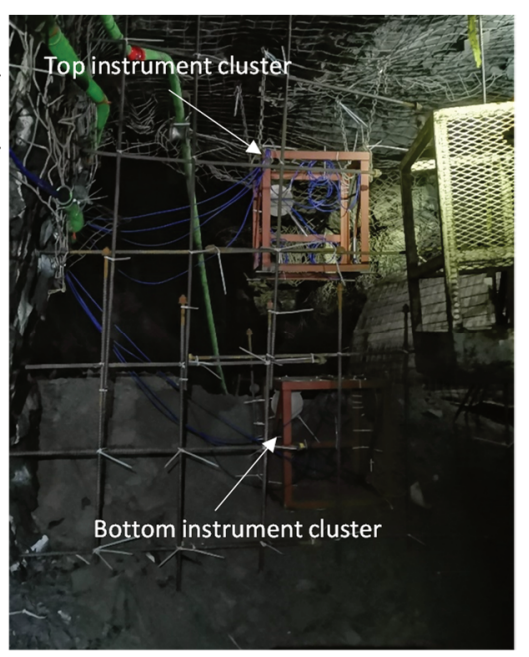

(b)

Figure 4 Stope 260-876-1 BLK1: (a) Long section view of the stope; (b) Fill fence instrument cluster locations

Table 1 Summary of backfilling delivery based on operator notes

\begin{tabular}{|c|c|c|c|c|}
\hline Pour & $\# 1$ & $\# 2$ & $\# 3$ & $\# 4$ \\
\hline Flush & $7 / 29 / 202021: 30$ & $7 / 31 / 202001: 30$ & $7 / 31 / 202010: 10$ & - \\
\hline Start & 7/29/2020 23:00 & $7 / 31 / 202002: 00$ & $7 / 31 / 202010: 30$ & $7 / 31 / 202020: 30$ \\
\hline End & 7/30/2020 19:00 & 7/31/2020 09:00 & $7 / 31 / 2020$ 19:00 & $8 / 01 / 202002: 30$ \\
\hline Flush & $7 / 30 / 2020$ 19:20 & 7/31/2020 09:25 & $7 / 31 / 202019: 30$ & 8/01/2020 02:55 \\
\hline Pour (h) & 20.0 & 7.0 & 8.5 & 6.0 \\
\hline Cure (h) & 7.0 & 1.5 & 1.5 & - \\
\hline
\end{tabular}

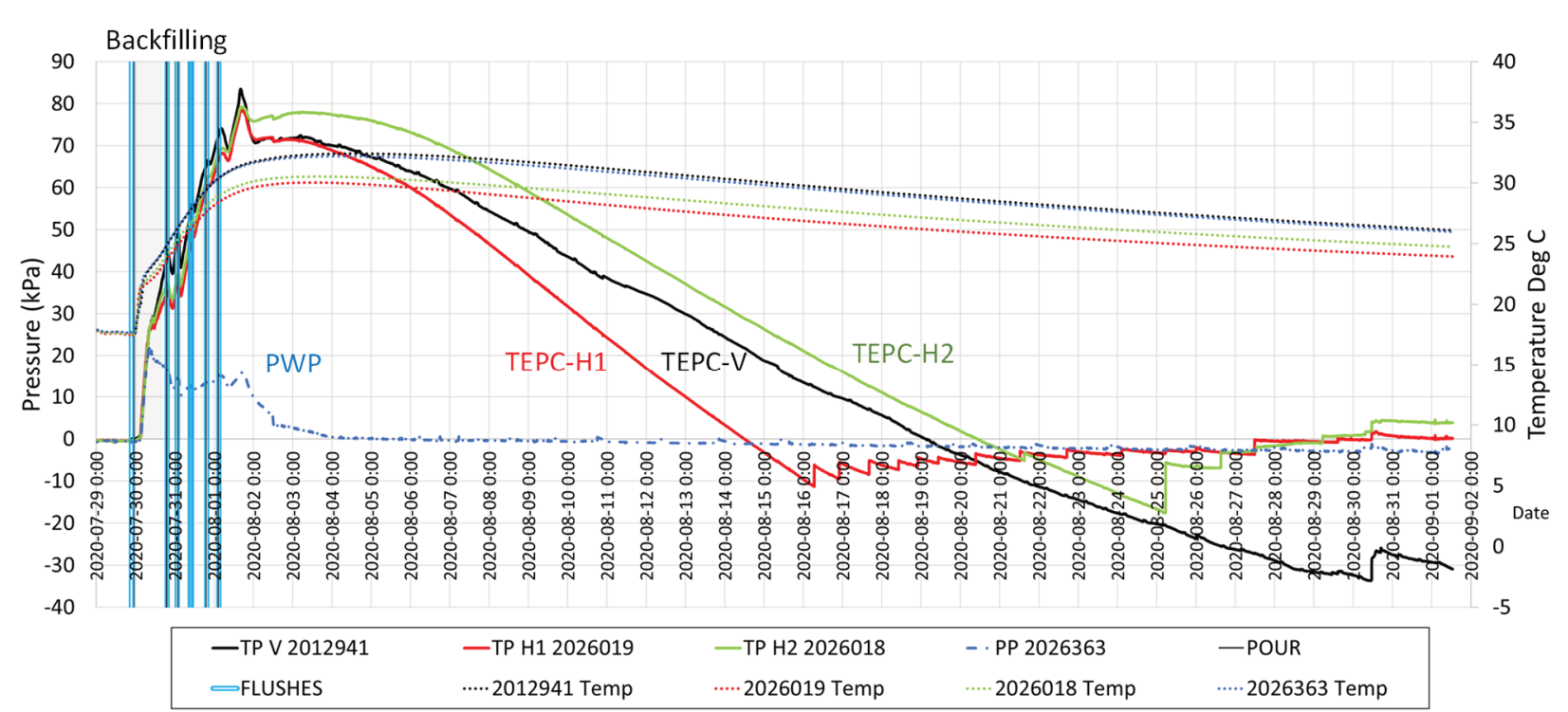

Figure 5 In-stope instrument cluster response to backfill pour of stope 260-876-1 BLK1 


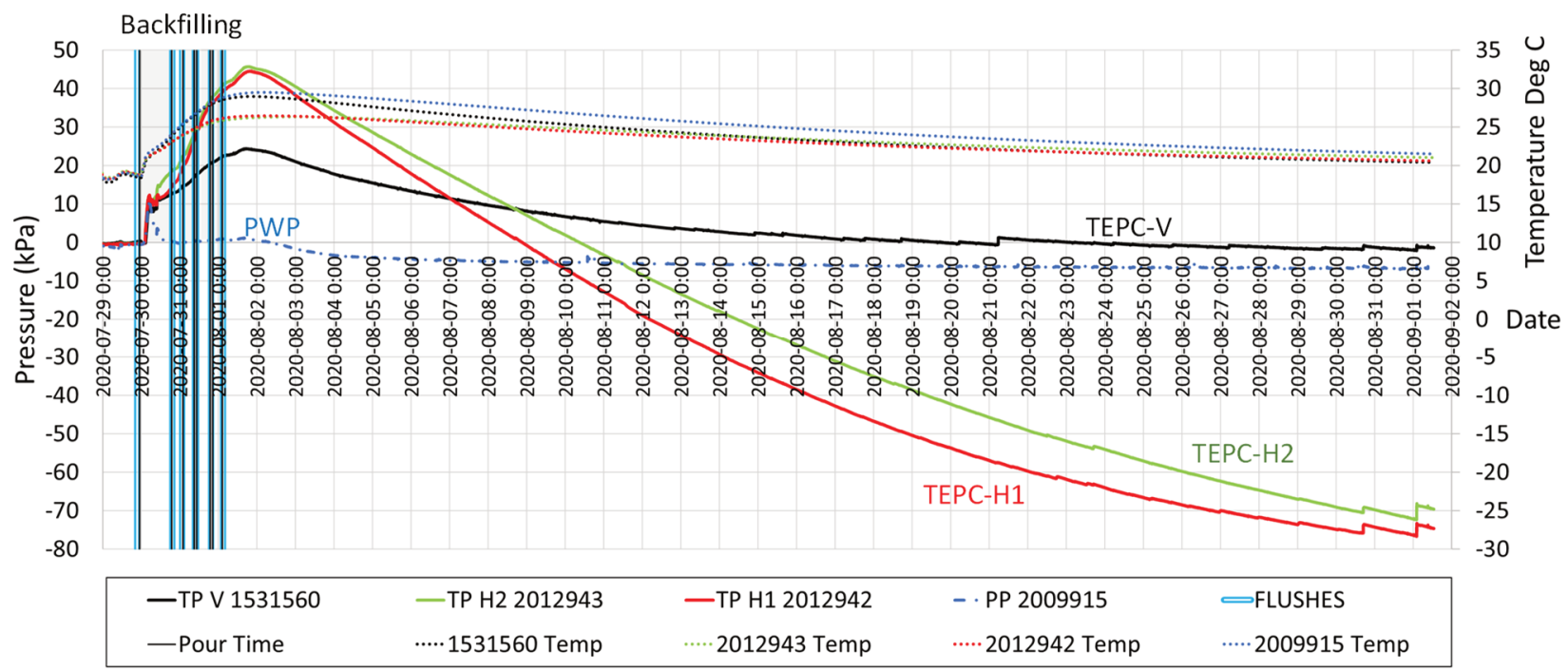

Figure 6 Bottom fill fence instrument cluster response to backfill pour of stope 260-876-1 BLK1

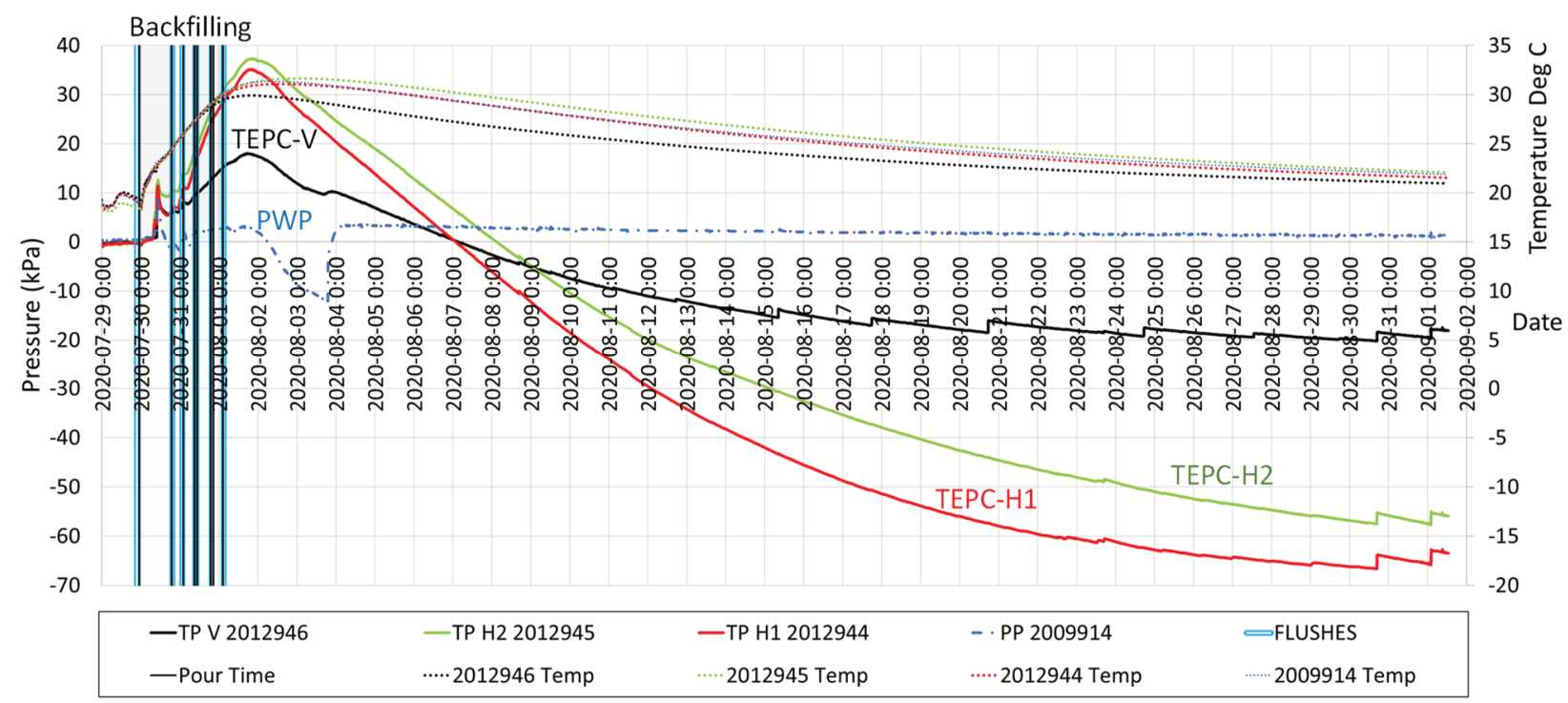

Figure 7 Top fill fence instrument cluster response to backfill pour of stope 260-876-1 BLK1

Following the $10 \mathrm{kPa}$ decrease in pressure, there was a slight gradual increase of pressure, followed by a gradual decrease in pressure. The gradual decrease had a rate of -4.9 to $-6.8 \mathrm{kPa} /$ day (or $18-25 \mathrm{kPa} /{ }^{\circ} \mathrm{C}$ ). The maximum change in pressure for the in-stope fence instruments was $-106 \mathrm{kPa}$ (vertical instrument). This decrease in pressure was captured in the other instrument clusters and is hypothesised to be primarily caused by thermal contraction. The decrease in pressure corresponds with a decrease in measured temperature, which was $-6^{\circ} \mathrm{C}$ from 4 August to 1 September 2020.

After the TEPCs recorded negative pressure measurements, minor spikes ( $\sim \mathrm{kPa}$ increases) of pressure were registered. It is assumed that these spikes are capturing the detachment of the CPB from the instruments, strengthening the thermal contraction effect hypothesis.

Figure 6 shows the results from the bottom fill fence instrumentation cluster, which was installed $0.9 \mathrm{~m}$ above the base of the fill fence. The pressure peaked approximately one day after the end of the entire pour with a maximum pressure of $44.4 \mathrm{kPa}$ acting on the fill fence, which is $35 \mathrm{kPa}$ less than the in-stope instrument reading in the same direction, on 2 August. After 2 August, the horizontal pressures gradually decreased at a rate of -4.7 to $-5.6 \mathrm{kPa} / \mathrm{day}$ (or $21.7-22.3 \mathrm{kPa} /{ }^{\circ} \mathrm{C}$ ). The maximum pressure change was measured to be $121 \mathrm{kPa}(\mathrm{H} 1$, pressure acting in the direction of the fill fence). The vertical pressure readings saw less pressure drop with a rate of only $\sim-1.8 \mathrm{kPa} /$ day (or $4.2 \mathrm{kPa} /{ }^{\circ} \mathrm{C}$ ) and a maximum pressure change of $24 \mathrm{kPa}$. The bottom 
instrument cluster also identified 'detachment' pressure spikes. The bottom instrument cluster captured the lowest negative pressure of all instruments at $-76 \mathrm{kPa}$.

Figure 7 shows the results of the top fill fence instrumentation cluster which was installed approximately $2.4 \mathrm{~m}$ above the base of the fill fence. The pressure peaked approximately one day after the end of the entire pour with a maximum pressure of $35 \mathrm{kPa}$ acting on the fill fence late on 1 August. After 1 August, the horizontal pressure gradually decreased at a rate of -4.8 to $-6.1 \mathrm{kPa} / \mathrm{day}$ (or $11-13 \mathrm{kPa} /{ }^{\circ} \mathrm{C}$ ), where the maximum pressure change was measured to be $-102 \mathrm{kPa}(\mathrm{H} 1$, pressure acting in the direction of the fill fence). The vertical pressure reading saw less of a pressure drop with a rate of only $3.6 \mathrm{kPa} / \mathrm{day}$ (or $7 \mathrm{kPa} /{ }^{\circ} \mathrm{C}$ ) and a maximum pressure change of $38 \mathrm{kPa}$.

Figure 7 also shows that the porewater pressure instrument measured a similar decrease in pressure as the TEPCs; however, once the instrument reached $-12 \mathrm{kPa}$, the pressure spiked back to near zero pressure readings. It should be noted that porewater pressure measurements are only reliable as long as the suction does not exceed $-20 \mathrm{kPa}$ (the typical air entry value of the piezometer tip, at which point cavitation occurs and air bubbles form). However, it is the authors' opinion that cavitation has occurred and the instrument is no longer reliable, based on comparison to other piezometer reading responses.

\subsection{Stope 512-595-1E BLK 3}

Stope 512-595-1E BLK3 was the third stope monitored during the program at RLO, the second to be tested on the shotcrete muck fence, and the first to be poured with $9 \%$ binder ( $36 \%$ class C fly ash, $64 \%$ cement) for the plug region. Stope 512-595-1E BLK3 is $24 \mathrm{~m}$ high, 13-21 m long, and 3.4-5.0 m wide from HW to FW with a dip of $\sim 60^{\circ}$. The muck fence was constructed in a drift that is approximately $5.0 \mathrm{~m}$ wide and $5.0 \mathrm{~m}$ high. The muck fence was positioned $\sim 1 \mathrm{~m}$ from the brow. The total time and pour time required for the stope were 87 and 58 hours, respectively. The detailed instrumentation results of this test stope are presented in Oke et al. (2021).

Data was collected for 30 days after the stope was completely filled with CPB. Figure 8 shows the results from the in-stope instrumentation cluster. Two to three days after the pour was completed, the vertical pressure and horizontal pressure (acting towards fill fence, $\mathrm{H} 1$ ) were at their highest pressures of 114 and $76 \mathrm{kPa}$, respectively. This pressure is only 26 and $17 \%$ of the expected hydrostatic pressure for the vertical and $\mathrm{H} 1$ pressures, respectively. The maximum pressure for the horizontal TEPC acting along the stope width (H2) occurred on 5 October (eight days after the end of pour), which was $60 \mathrm{kPa}$ ( $14 \%$ of hydrostatic pressure). This maximum pressure corresponded with the maximum temperature. The following results illustrate that all instruments gradually decreased in pressure to 85,29 , and $48 \mathrm{kPa}$ for the vertical and horizontal TEPCs ( $\mathrm{H} 1$ and $\mathrm{H} 2$ ), respectively, at the end of the test.

The gradual decrease had a rate of -1.1 to $-1.9 \mathrm{kPa} /$ day for the vertical and horizontal $(\mathrm{H} 1)$ instruments. The maximum change in pressure for the in-stope fill fence was $-48 \mathrm{kPa}$ ( $\mathrm{H} 1$ instrument). This decrease in pressure was captured in the fill fence instrument clusters, as shown in Figure 9 and is mainly caused by hypothesised thermal contraction. The decrease in pressure corresponds with a decrease in measured temperature, which was $-2^{\circ} \mathrm{C}$ from 5 to 27 October at a rate of 17 to $28 \mathrm{kPa} /{ }^{\circ} \mathrm{C}$.

It is important to note that the pore pressure instrument captured a negative reading (Figure 9). This negative reading could be caused by the water pressure dropping below the original ambient air pressure. This result is an indication that effective stresses are increasing. 


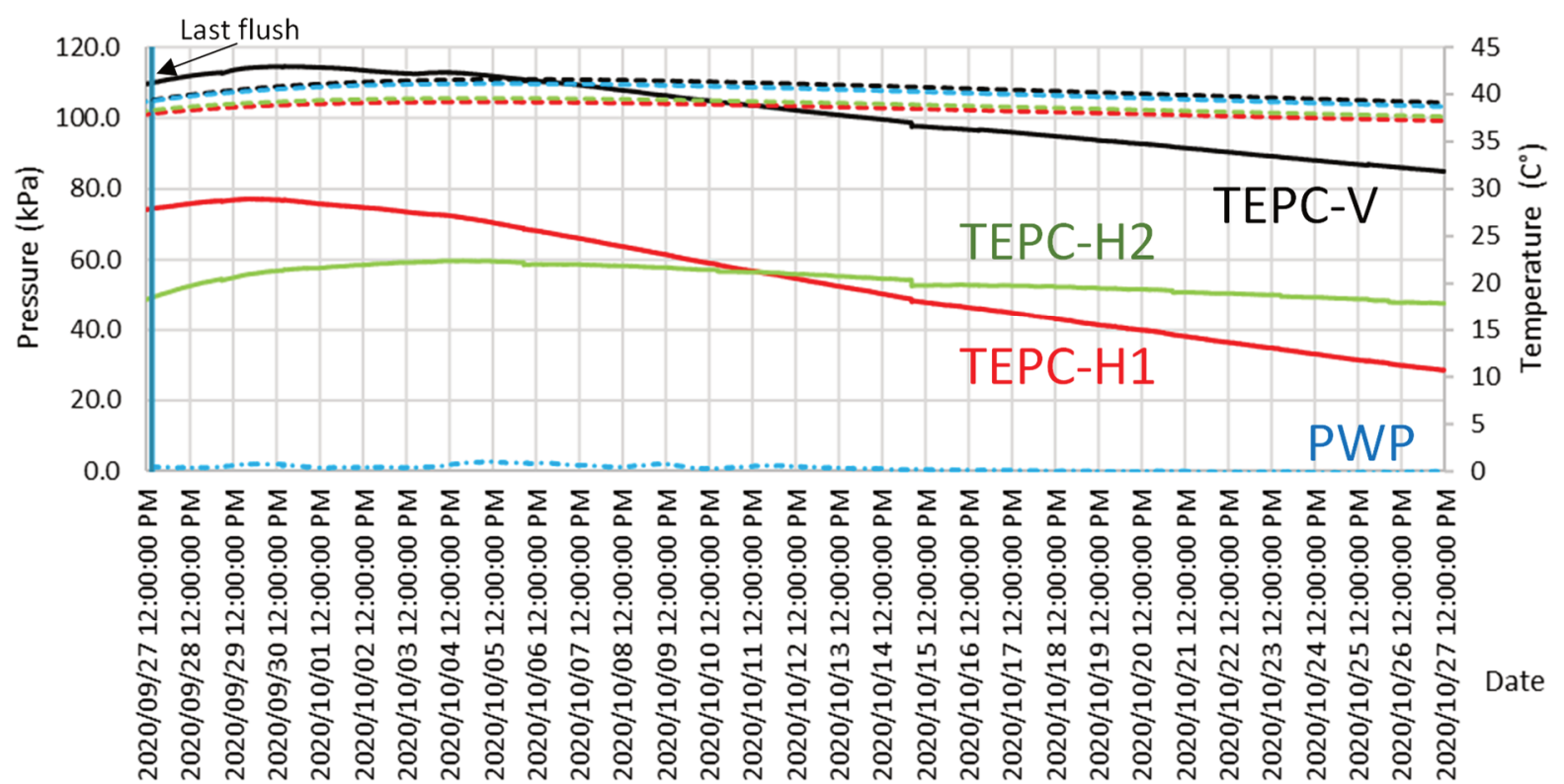

\begin{tabular}{|lll|}
\hline- TEPC-V-2026027 & -TEPC-H1-2026021 & TEPC-H2-2026026 \\
- - PP-Instope-2026362 & POUR & FLUSHES \\
--- - Temp -V-2026027 & -----Temp -H1-2026021 & ---- Temp -H2-2026026 \\
\hline
\end{tabular}

Figure 8 In-stope instrument cluster response during curing of stope 512-595-1E BLK3

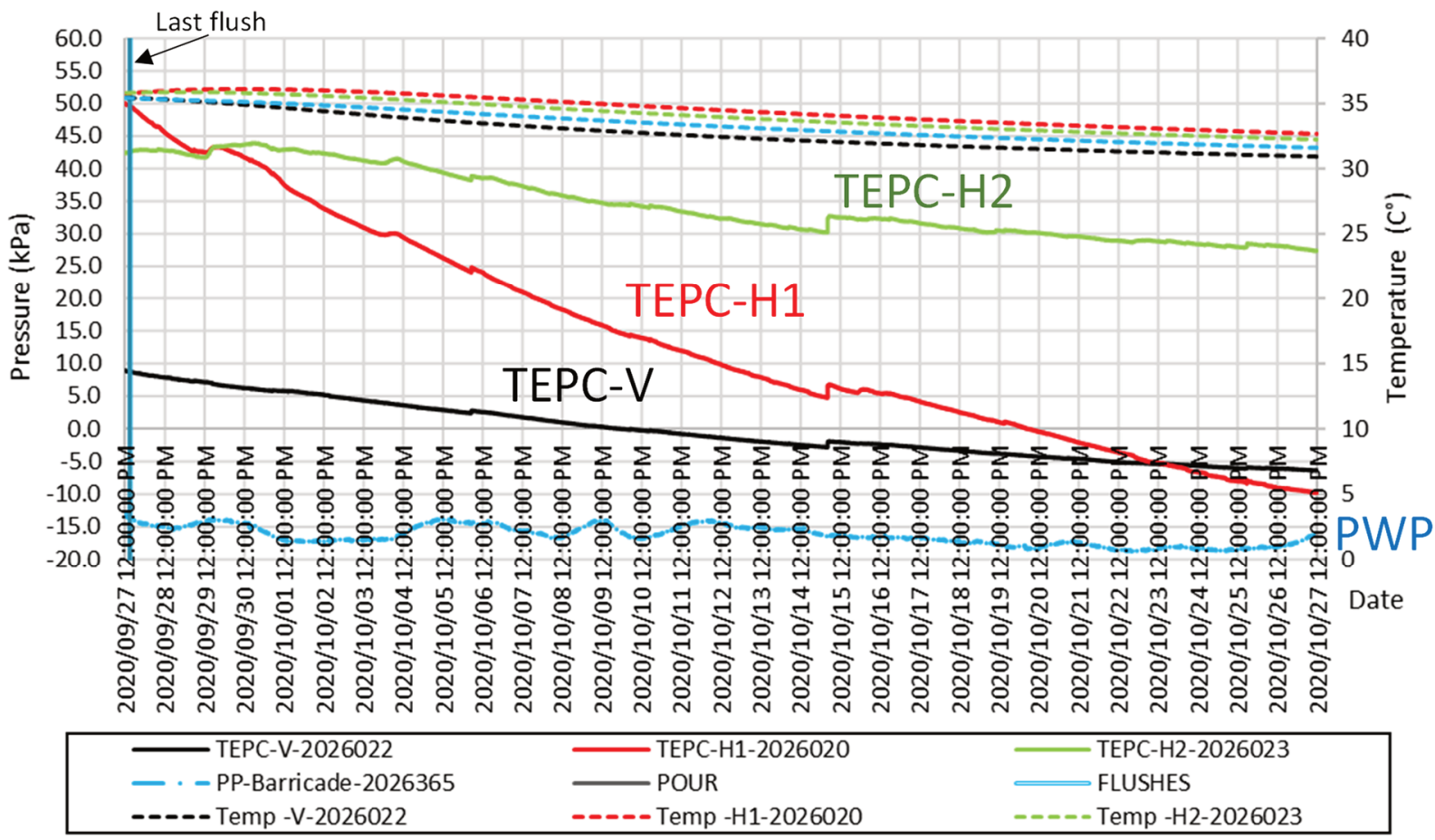

Figure 9 Fill fence instrument cluster response during curing of stope 512-595-1E BLK3

\subsection{Stope 192-979-1E BLK 4}

Stope 192-979-2E BLK4 was the fourth stope monitored during the program at RLO, the second to be tested on the rebar-reinforced shotcrete fill fence, and the second to be poured with $9 \%$ binder ( $41 \%$ class C fly ash, $\sim 59 \%$ cement) for the plug region. Stope 192-979-2E BLK4 (Figure 10) is $20 \mathrm{~m}$ high, 12-14 m long, and typically 3.0-4.3 m wide ( $\max 5.8 \mathrm{~m}$ wide within bottom drift) from HW to FW with a dip of $\sim 72^{\circ}$. The rebar fill fence was constructed in a drift that is approximately $4.7 \mathrm{~m}$ wide and $4.4 \mathrm{~m}$ high. The fill fence was positioned $\sim 4 \mathrm{~m}$ from the brow. It took six different pours to fill the stope, as shown in Table 2 . The initial pour had to be 
stopped due to a leak in the paste distribution line. The total time and pour time required for the stope were 65 and 36 hours, respectively; less if the first pour attempt and repair is ignored (61 and 35 hours, respectively).

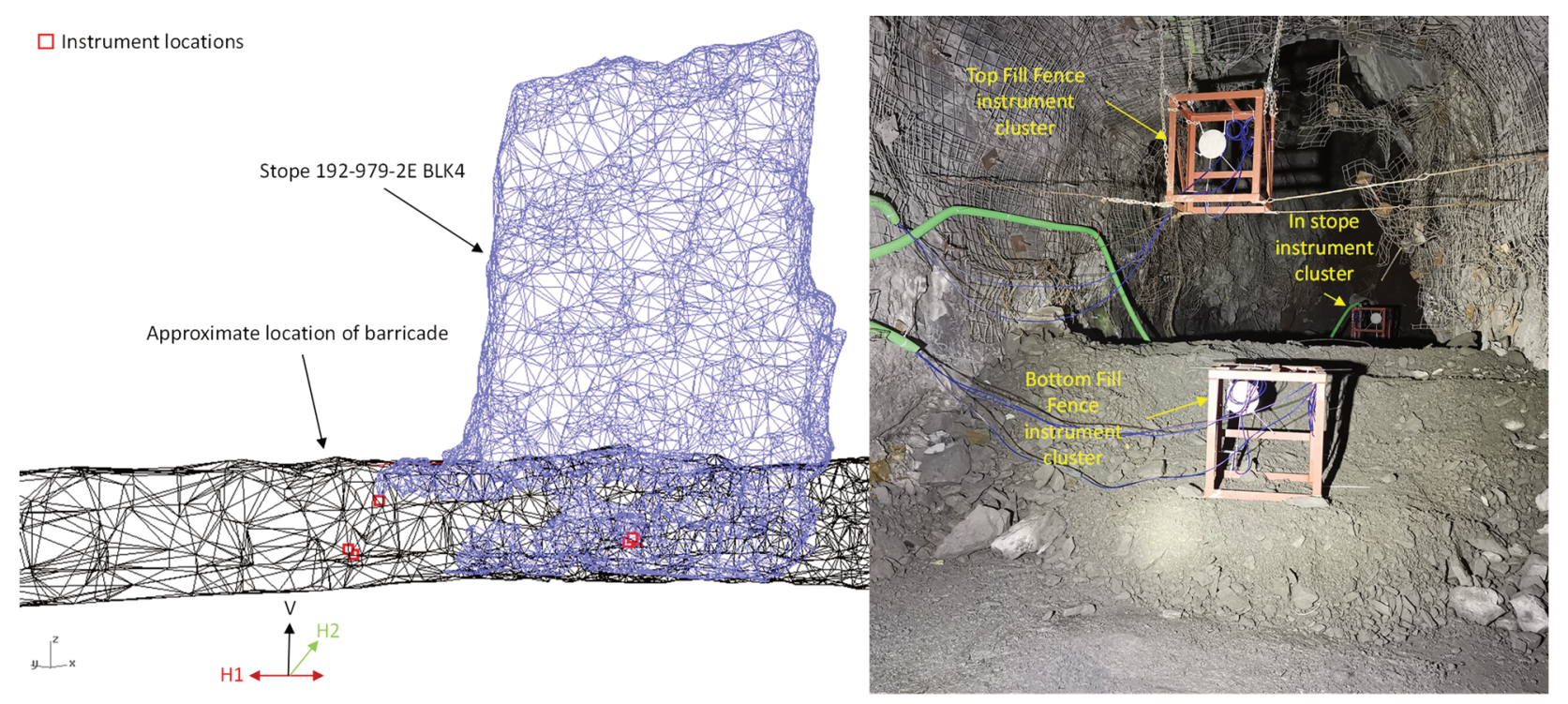

Figure 10 Instrumentation location in stope 192-979-2E BLK4 and instrumentation notation

Table 2 Summary of backfilling delivery based on operator notes

\begin{tabular}{lllllll}
\hline Pour & $\mathbf{1}$ & $\mathbf{2}$ & $\mathbf{3}$ & $\mathbf{4}$ & $\mathbf{5}$ & $\mathbf{6}$ \\
\hline Flush & $12 / 28 / 2020$ & $12 / 28 / 2020$ & $12 / 29 / 2020$ & $12 / 29 / 2020$ & $12 / 30 / 2020$ & $12 / 30 / 2020$ \\
& $8: 35$ & $12: 45$ & $1: 35$ & $19: 45$ & $8: 55$ & $19: 55$ \\
Start & $12 / 28 / 2020$ & $12 / 28 / 2020$ & $12 / 29 / 2020$ & $12 / 29 / 2020$ & $12 / 30 / 2020$ & $12 / 30 / 2020$ \\
& $9: 45$ & $14: 00$ & $2: 30$ & $20: 30$ & $10: 45$ & $20: 30$ \\
End & $12 / 28 / 2020$ & $12 / 28 / 2020$ & $12 / 29 / 2020$ & $12 / 30 / 2020$ & $12 / 30 / 2020$ & $12 / 31 / 2020$ \\
& $10: 30$ & $23: 40$ & $11: 00$ & $2: 45$ & $14: 50$ & $2: 50$ \\
\multirow{3}{*}{ Flush } & $12 / 28 / 2020$ & $12 / 29 / 2020$ & $12 / 29 / 2020$ & $12 / 30 / 2020$ & $12 / 30 / 2020$ & $12 / 31 / 2020$ \\
& $11: 50$ & $0: 00$ & $11: 20$ & $3: 10$ & $15: 10$ & $3: 10$ \\
\multirow{3}{*}{ Pour (h) } & 0.8 & 9.7 & 8.5 & 6.3 & 4.1 & 6.3 \\
Cure (h) & 3.5 & 2.8 & 9.5 & 8.0 & 5.7 & - \\
\hline
\end{tabular}

Data was collected for 36 days after the stope was completely filled with CPB. Figure 11 shows the results from the in-stope instrumentation cluster. The vertical pressure (TEPC-V) and horizontal pressures (TEPC-H1 and TEPC-H2) were at their highest values six to nine days after the pour was completed. The peak vertical pressures registered $194 \mathrm{kPa}, \mathrm{H} 1$ registered $144 \mathrm{kPa}$, and $\mathrm{H} 2$ registered $173 \mathrm{kPa}$. These maximum pressures corresponded with the maximum temperature, which is an indication of constrained thermal expansion. The rate of increase ranged from $13.8 \mathrm{kPa} /{ }^{\circ} \mathrm{C}$ for the vertical instrument and $23.2 \mathrm{kPa} /{ }^{\circ} \mathrm{C}$ for the $\mathrm{H} 2$ instrument over a temperature change of 3.2 to $4.7^{\circ} \mathrm{C}$. Even with the thermal expansion, the instruments only saw 40 to $54 \%$ of the maximum potential hydrostatic pressure.

After the maximum pressure and temperature were reached, all instruments gradually decreased in pressure until the end of the test. The rate of this decrease was found to range from $18.5 \mathrm{kPa} /{ }^{\circ} \mathrm{C}$ for the $\mathrm{H} 2$ instrument, to $34.8 \mathrm{kPa} /{ }^{\circ} \mathrm{C}$ for the $\mathrm{H} 1$ instrument. The $\mathrm{H} 1$ instrument also shows a sign of detachment (CPB pulling away from the instrument due to CPB shrinkage) on 4 February, after the instrument registered negative pressures. 
On 28 January, there was a slight increase in TEPC instrument pressures, while the piezometer readings moved from negative pressure to zero pressure by 30 January. No seismic events were recorded during this time period, and based on the increase in the piezometer reading, it is assumed that water was entering the stope from diamond drillholes.

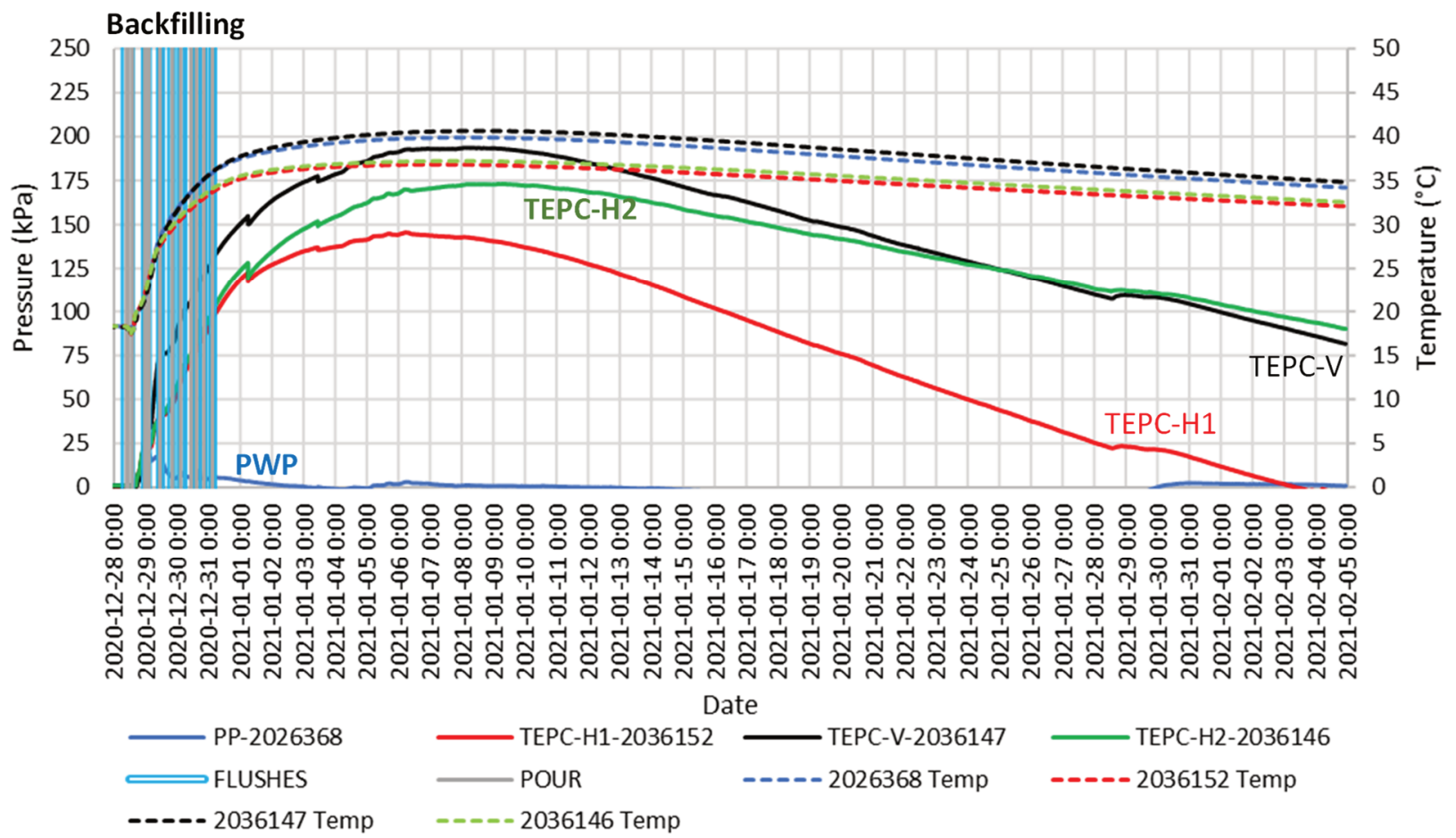

Figure 11 In-stope instruments cluster response to CPB backfilling of stope 192-979-2E BLK4

Figure 12 shows the results of the bottom instrument cluster on the fill fence. The $\mathrm{H} 1$ instrument recorded a maximum pressure of $83 \mathrm{kPa}, 21$ hours after the pour was completed. On 1 January, a seismic event occurred (moment magnitude of $0.3, \sim 80 \mathrm{~m}$ away from the instruments), resulting in a sudden pressure drop of $\sim 30 \mathrm{kPa}$. The rate of pressure decrease was $18.4 \mathrm{kPa} /{ }^{\circ} \mathrm{C}$. The vertical instrument and piezometer had relatively constant pressure during the backfill curing process. The piezometer recorded multiple decreases of pressure during the remainder of the test. It is unclear what has caused this fluctuation in pressure, although it may be caused by a slight displacement of the cluster as it was positioned on the side of a small muck berm (constructed to protect the workers from material falling from the stope during installation of the rebar fence).

The top fill fence TEPC instrument experienced an increase of pressure from 73 to $112 \mathrm{kPa}$ at the end of the pour, as shown in Figure 13. This pressure increase is believed to be driven by constrained thermal expansion. Once the last pour was finished (pour \#6), the instrument measured an increase of $4.8^{\circ} \mathrm{C}$, which resulted in an expansion rate of $8 \mathrm{kPa} /{ }^{\circ} \mathrm{C}$. After this maximum pressure, the pressure decreased due to backfill contraction at a rate of $22.6 \mathrm{kPa} /{ }^{\circ} \mathrm{C}$. Once the TEPC reached its most negative value, detachment occurred multiple times until the pressure stabilised at $\sim-50 \mathrm{kPa}$.

\subsection{Summary of test program}

The test program captured pressures increasing (backfill expanding) and decreasing (backfill 'contracting' due to pressure drop) with temperature change as shown in Table 3. The stope 321-865-1W Blk3 does not have any values as a seismic event occurred resulting in an irregular response; thus, it was not possible to capture the exact expansion or contraction rates. The range of expansion and contraction varies from test to test as well as depending on the orientation of the instruments. There was no clear difference in the response when different binders were used. There appears to be a higher level of expansion and contraction for the in-stope 
instruments when compared to the instruments installed on the fill fence. Similarly, H1 pressure readings appear to have a higher sensitivity to expansion and contraction.

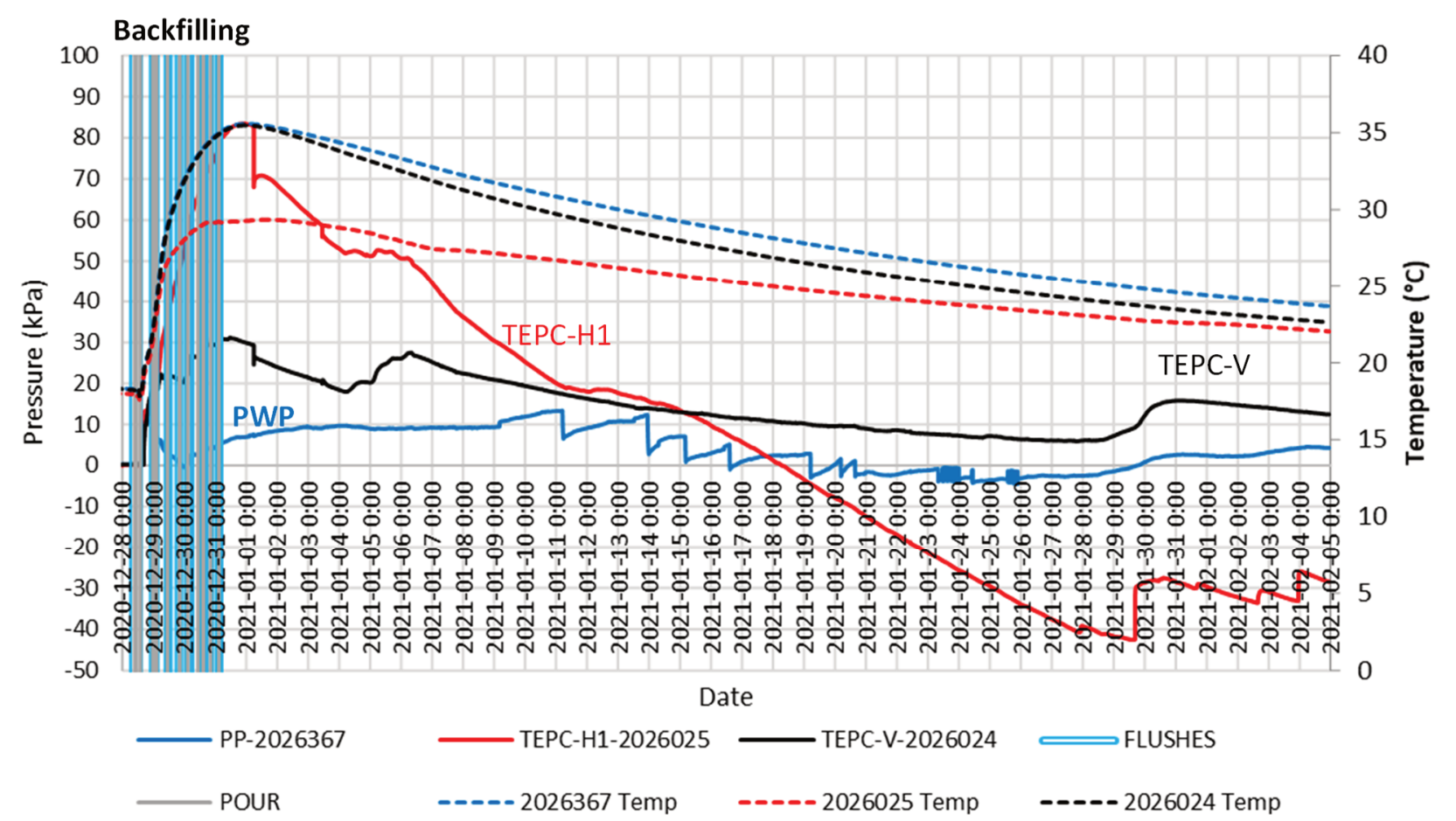

Figure 12 Bottom of the fill fence instrument cluster response to CPB backfilling of stope 192-979-2E BLK4

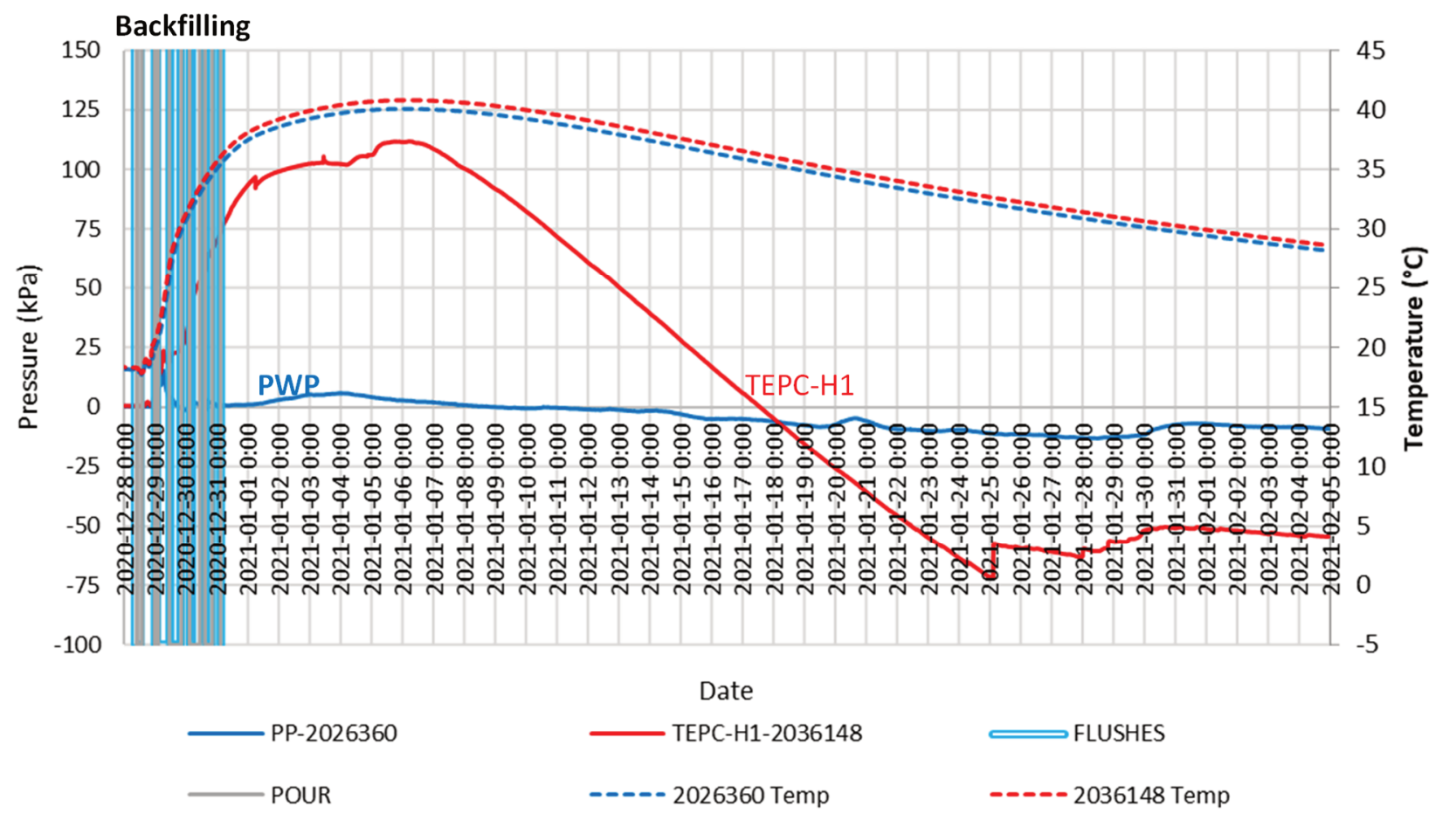

Figure 13 Top of the fill fence instrument cluster response to CPB placement of stope 192-979-2E BLK4 
Table 3 Rates of recorded expansion and contraction at RLO. Note: If fill fence has two instrument clusters, the top instrument results are shown above within the table

\begin{tabular}{|c|c|c|c|c|c|c|c|c|c|c|c|c|c|}
\hline \multirow[t]{3}{*}{ Stope } & \multirow[t]{3}{*}{ Binder (\%) } & \multicolumn{6}{|c|}{ Expansion $\left(\mathrm{kPa} /{ }^{\circ} \mathrm{C}\right)$} & \multicolumn{6}{|c|}{ Contraction $\left(\mathrm{kPa} /{ }^{\circ} \mathrm{C}\right)$} \\
\hline & & \multicolumn{3}{|c|}{ In-stope } & \multicolumn{3}{|c|}{ Fill fence } & \multicolumn{3}{|c|}{ In-stope } & \multicolumn{3}{|c|}{ Fill fence } \\
\hline & & H1 & $\mathrm{H} 2$ & $\mathbf{v}$ & H1 & H2 & v & H1 & $\mathrm{H} 2$ & $\mathbf{v}$ & H1 & $\mathrm{H} 2$ & $\mathbf{V}$ \\
\hline 321-865-1W Blk3 & 5 & - & - & - & - & - & - & - & - & - & - & - & - \\
\hline \multirow{2}{*}{ 260-876-1 Blk1 } & \multirow{2}{*}{5} & \multirow{2}{*}{-} & \multirow{2}{*}{-} & \multirow{2}{*}{-} & 6 & 6 & 9 & \multirow{2}{*}{25} & \multirow{2}{*}{21} & \multirow{2}{*}{18} & 13 & 11 & 7 \\
\hline & & & & & 26 & 13 & 6 & & & & 22 & 22 & 4 \\
\hline 512-595-1E Blk3 & 9 & 2 & 9 & 4 & - & - & - & 28 & 6 & 17 & 15 & 5 & 4 \\
\hline \multirow{2}{*}{ 192-979-1E Blk4 } & \multirow{2}{*}{9} & \multirow{2}{*}{16} & \multirow{2}{*}{23} & \multirow{2}{*}{14} & 8 & NA & NA & \multirow{2}{*}{35} & \multirow{2}{*}{21} & \multirow{2}{*}{19} & 23 & NA & NA \\
\hline & & & & & - & NA & - & & & & 18.4 & NA & - \\
\hline
\end{tabular}

\section{Discussion}

After the completion of test stope 192-979-1E Blk4, the expansion resulted in pressures that exceeded the allowable pressure ( $\sim 90 \mathrm{kPa}$ ) for the fill fence (see Oke et al. 2021 for additional information on allowable pressure). Upon inspection of the fill fence, there was no damage to the structure. It is important to note that this expansion occurs when the backfill has adequate strength (i.e. self-supporting), therefore, there is minimal risk if the fill fence cracks/breaks when other quality assurance/quality control protocols are in place.

Contraction was typically captured after the constrained thermal expansion and the temperature start to decrease (pressure dissipation). Capturing this contraction is important, especially within the $9 \%$ binder, as this binder is used for planned inverse stopes underneath the plug. At RLO, a sill pillar is left between the backfill and the stope underneath, but at other operations, the backfill can be designed to be left open. Often, these designs assume a 'conservative' no confining pressure on the backfill during undercutting. These contraction results indicate that not only can the backfill be unconfined, but it could also possibly be detached. If cracking is developed during shrinkage, coupled with cold joints, blocks could easily be formed resulting in back instability. However, no instrumentation during the RLO study was installed in position above future inverse stopes, so it was not possible to capture the effects of undercut mining on the stress state of the backfill (i.e. if increasing the extraction near the stope results in the backfill to be more confined) as conducted in Seymour et al. (2019).

The pressure dissipation is believed to be caused primarily by thermal contraction, but chemical shrinkage and other factors also play a role. It is recommended that future work be carried out in order to quantify the contribution of both the chemical shrinkage and thermal contraction in order to better understand the behaviour of the CPB.

\section{Conclusion}

The results of the testing captured expansion of the backfill that was most likely due to thermal expansion. Furthermore, when the temperature decreased after the test, the backfill experienced dissipated pressure or contraction. This dissipation or contraction has been hypothesised as being mainly driven by a hypothetical thermal contraction. The contribution of chemical shrinkage or other factors is unknown and still needs to be quantified with additional in situ or laboratory studies. Understanding the potential of thermal dissipation and contraction is important for undercutting analysis and understanding the stability of CPB if exposed from underneath, as confining stress is a major parameter in the design of backfill sill pillar strength. 
Future work will consist of investigating the contraction theory as a function of binder since the current dataset is limited. Additionally, the assumption that the CPB detached from the pressure cells needs to be further investigated to confirm the hypothesised response.

\section{Acknowledgement}

The authors thank the Red Lake operation of Evolution Mining Management Team and Evolution Leadership Team for allowing them to publish this study. We also thank the Evolution Production Team in assisting us with the logistics and placement of instrumentation in order to obtain the invaluable information.

\section{References}

Belem, T, Fourie, A, Fahey, M 2010, 'Measurement of volume change in cemented mine backfills at early ages', in R Jewell \& AB Fourie (eds), Proceedings of the 1st International Seminar on Reduction of Risk in the Management of Tailings and Mine Waste, Australian Centre for Geomechanics, Perth, pp. 449-462, https://doi.org/10.36487/ACG_rep/1008_37_Belem

Helinski, M, Fourie, A, Fahey, M \& Ismail, M 2007, 'Assessment of the self-desiccation process in cemented mine backfills', Canadian Geotechnical Journal, vol. 44, no. 10, pp. 1148-1156.

Oke, J \& Hashemi, A 2021, 'In-situ backfill monitoring database', in AB Fourie \& D Reid (eds), Paste 2021: Proceedings of the 24th International Conference on Paste, Thickened and Filtered Tailings, Australian Centre for Geomechanics, Perth, pp. 353-368.

Oke, J, Hawley, K, Belem, T \& Hashemi, A 2021, 'Paste backfill continuous pour: Red Lake operations case study', in AB Fourie \& D Reid (eds), Paste 2021: Proceedings of the 24th International Conference on Paste, Thickened and Filtered Tailings, Australian Centre for Geomechanics, Perth, pp. 381-396.

Seymour, JB, Martin, LA, Raffaldi, MJ, Warren, SN \& Sandbak, LA 2019, 'Long-term stability of a $13.7 \times 30.5-\mathrm{m}(45 \times 100-\mathrm{ft})$ undercut span beneath cemented rockfill at the Turquoise Ridge mine, Nevada', Rock Mechanics and Rock Engineering, vol. 52, no. 12, pp. 4907-4923.

Thompson, BD, Simon, D, Grabinsky, MW, Counter, DB \& Bawden, WF 2014a, 'Constrained thermal expansion as a causal mechanism for in situ pressure in cemented paste and hydraulic backfilled stopes', in Y Potvin \& T Grice (eds), Proceedings of the Eleventh International Symposium on Mining with Backfill, Australian Centre for Geomechanics, Perth, pp. 365-378, https://doi.org/ 10.36487/ACG_rep/1404_29_Thompson

Thompson, BD, Hunt, T, Malek, F, Grabinsky, MW \& Bawden, WF 2014b, 'In situ behaviour of cemented hydraulic and paste backfills and the use of instrumentation in optimising efficiency', in Y Potvin \& T Grice (eds), Proceedings of the Eleventh International Symposium on Mining with Backfill, Australian Centre for Geomechanics, Perth, pp. 337-350, https://doi.org/10.36487/ ACG_rep/1404_27_Thompson 